BNL-114340-2017-JA

\title{
Single Atomic Iron Catalysts for Oxygen Reduction in Acidic Media: Particle Size Control and Thermal Activation
}

\author{
H. Zhang, D. Su
}

Accepted by the JACS

September 2017

Center for Functional Nanomaterials

Brookhaven National Laboratory

\author{
U.S. Department of Energy \\ USDOE Office of Science (SC), \\ Basic Energy Sciences (BES) (SC-22)
}

Notice: This manuscript has been authored by employees of Brookhaven Science Associates, LLC under Contract No. DE-SC0012704 with the U.S. Department of Energy. The publisher by accepting the manuscript for publication acknowledges that the United States Government retains a non-exclusive, paid-up, irrevocable, world-wide license to publish or reproduce the published form of this manuscript, or allow others to do so, for United States Government purposes. 


\section{DISCLAIMER}

This report was prepared as an account of work sponsored by an agency of the United States Government. Neither the United States Government nor any agency thereof, nor any of their employees, nor any of their contractors, subcontractors, or their employees, makes any warranty, express or implied, or assumes any legal liability or responsibility for the accuracy, completeness, or any third party's use or the results of such use of any information, apparatus, product, or process disclosed, or represents that its use would not infringe privately owned rights. Reference herein to any specific commercial product, process, or service by trade name, trademark, manufacturer, or otherwise, does not necessarily constitute or imply its endorsement, recommendation, or favoring by the United States Government or any agency thereof or its contractors or subcontractors. The views and opinions of authors expressed herein do not necessarily state or reflect those of the United States Government or any agency thereof. 


\title{
Single Atomic Iron Catalysts for Oxygen Reduction in Acidic Media: Particle Size Control and Thermal Activation
}

\author{
Hanguang Zhang ${ }^{\dagger}$, Sooyeon Hwang ${ }^{\ddagger}$, Maoyu Wang ${ }^{\S}$, Zhenxing Feng ${ }^{\S}$, Stavros Karakalos ${ }^{\perp}$, Langli Luo", \\ Zhi Qiao ${ }^{\dagger}$, Xiaohong Xie"l, Chongmin Wang", Dong Su${ }^{\star}$, Yuyan Shaoll*, and Gang $\mathrm{Wu}^{\dagger}$,* \\ 'Department of Chemical and Biological Engineering, University at Buffalo, The State University of New York, Buffalo, \\ New York 14260, United States \\ ${ }^{\ddagger}$ Center for Functional Nanomaterials, Brookhaven National Laboratory, Upton, New York 11973, United States \\ ${ }^{\S}$ School of Chemical, Biological, and Environmental Engineering, Oregon State University, Corvallis, Oregon 97331, United \\ States \\ ${ }^{\perp}$ Department of Chemical Engineering, University of South Carolina, Columbia, South Carolina 29208, United States. \\ "Pacific Northwest National Laboratory, Richland, Washington 99352, United States \\ KEYWORDS: Atomic iron catalysts; electrocatalysis; oxygen reduction; metal-organic frameworks; size control
}

\begin{abstract}
It remains a grand challenge to replace platinum group metal (PGM) catalysts with earth abundant materials for the oxygen reduction reaction (ORR) in acidic media, which is crucial for large-scale deployment of proton exchange membrane fuel cells (PEMFCs). Here, we report a high-performance atomic Fe catalyst derived from chemically Fe-doped zeolitic imidazolate frameworks (ZIFs) by directly bonding Fe ions to imidazolate ligands within 3D frameworks. Although the ZIF was identified as a promising precursor, the new synthetic chemistry enables well-dispersed atomic Fe sites embedded into porous carbon without the formation of aggregates. Catalyst particle sizes are tunable through synthesizing Fe-doped ZIF nanocrystal precursors in a wide range from 20 to $1000 \mathrm{~nm}$ followed by one-step thermal activation. Similar to Pt nanoparticles, the unique size control without altering chemical properties is able to increase the number of PGM-free active sites. The best ORR activity is measured with the catalyst with a size of $50 \mathrm{~nm}$. Further size reduction to $20 \mathrm{~nm}$ leads to significant particle agglomeration thus decreasing the activity. Using the homogeneous atomic Fe model catalysts, we elucidated the active site formation process through correlating measured ORR activity with the chemical bond changes of precursors during thermal activation up to $1100^{\circ} \mathrm{C}$. The critical temperature to form active sites is $800^{\circ} \mathrm{C}$ associated with a new $\mathrm{Fe}$ species with reduced oxidation number (from $\mathrm{Fe}^{3+}$ to $\mathrm{Fe}^{2+}$ ) likely bonded with pyridinic $\mathrm{N}\left(\mathrm{FeN}_{4}\right)$ embedded into carbon planes. Further increasing temperature leads to continuously enhanced activity, linking to the rise of graphitic $\mathrm{N}$ and Fe-N species. The new atomic Fe catalyst has achieved respectful ORR activity in challenging acidic media $\left(0.5 \mathrm{M} \mathrm{H}_{2} \mathrm{SO}_{4}\right)$ showing a half-wave potential of $0.85 \mathrm{~V} \mathrm{vs}$. RHE, only leaving $30 \mathrm{mV}$ gap with Pt/C $\left(60 \mu \mathrm{g}_{\mathrm{Pt}} / \mathrm{cm}^{2}\right)$. Enhanced stability is attained with the same catalyst only losing $20 \mathrm{mV}$ after 10,000 potential cycles $(0.6$ to $1.0 \mathrm{~V})$ in $\mathrm{O}_{2}$ saturated acid. The high-performance atomic Fe PGM-free catalyst would hold a great promise to replace Pt for future PEMFCs.
\end{abstract}

\section{Introduction}

Proton exchange membrane fuel cells (PEMFCs) represent a promising sustainable energy conversion technology. However, their wide application is hindered by the prohibitive cost. According to a U.S. DOE estimation, platinum group metal (PGM) catalysts in PEMFC systems account for about $50 \%$ of the total cost at large scale production. ${ }^{1}$ Therefore, during past ten years, significant effort has been made on the development of PGM-free oxygen reduction reaction (ORR) cathode catalysts using earthabundant elements. ${ }^{2-11}$ Due to the commercial availability of proton conducting Nafion ${ }^{\circledR}$ membranes, acidic PEMFCs are more promising applications relative to alkaline membrane fuel cells. However, the ORR over PGM-free catalysts in acidic media faces greater challenges because of more sluggish kinetics and corrosive environments. ${ }^{2,6,7}$ Compared to other studied materials (oxides, sulfides, carbides), ${ }^{12-14}$ carbon-based catalysts hold greater promise for the ORR in acids due to good stability, high surface areas, excellent electrical conductivity, and flexible dopants. ${ }^{11,15-18}$ Especially, the key to enhancing catalytic activity of carbon is proper doping with heteroatoms $(e . g ., \mathrm{N}, \mathrm{S}, \mathrm{P})$ and transition metals (e.g., $\mathrm{Fe}$ or $\mathrm{Co}$ ) for optimal electronic and geometric structures. ${ }^{19}$ Density functional theory (DFT) calculation suggested that the co-doping of $\mathrm{Fe}$ and $\mathrm{N}$ in the form of possible $\mathrm{FeN}_{4}$ sites could be as active as $\mathrm{Pt}$ for the $\mathrm{O}_{2}$ adsorption and subsequent $\mathrm{O}=\mathrm{O}$ bond breaking during the ORR. ${ }^{20-23}$ High-performance Fe-N-C catalysts would be designed by arranging $\mathrm{N}$ and $\mathrm{Fe}$ atoms to form optimal $\mathrm{FeN}_{4}$ sites uniformly dispersed into porous carbon. ${ }^{24,25}$ However, current Fe-N-C catalysts are still lack of sufficient activity and long-term durability and are not yet able to replace $\mathrm{Pt}$ catalysts for PEMFC applications. ${ }^{2}$ A key step to further enhance performance of $\mathrm{Fe}-\mathrm{N}-\mathrm{C}$ catalysts is to increase density of ORR active $\mathrm{FeN}_{4}$ sites within a 3D architecture. ${ }^{26-29}$ However, previous work has indicated that simply raising the Fe content in precursors during catalyst synthesis is not effective, as this only leads to the formation of inactive metallic iron, oxide, or carbide, instead of atomically dispersed active $\mathrm{FeN}_{4}$ sites. $^{26}$ Traditional Fe-N-C catalysts are prepared by pyrolyzing a composite of physically mixed iron salts, nitrogen-carbon precursors, and high-surface area carbon black supports, followed by a tedious acidic leaching 
and second heating treatments. ${ }^{5,7,24,29-35}$ These approaches often lead to a heterogeneous morphology with poor control of local environments for active sites. This also represents a significant challenge for fundamental understanding of structure-property relationship of Fe-N-C ctalysts for rational design.

Metal-organic frameworks (MOFs), which are constructed by bridging metal atoms and ligands into 3D ordered crystal frameworks with large volume of micropores and high surface area, provide a good platform to design Fe-N-C catalysts. ${ }^{10,32,36-41}$ However, current approaches are limited to simply utilizing MOF particles to replace traditional carbon supports mixing with other nitrogen/carbon and metal sources by using physical ball-milling and wetting implements. ${ }^{36,39,41,42}$ As a result, these MOF composite precursors themselves were still highly heterogeneous with poor control in chemistry and structure. ${ }^{26}$ Due to the heterogeneity, many $\mathrm{N}$ and Fe-related species exist in catalysts, masking the real active sites. To prepare homogenous catalysts, recently the zinc-based zeolite imidazole framework (ZIF-8) are studied to encapsulate guest iron containing molecules including $\mathrm{Fe}(\mathrm{acac})_{3}{ }^{43}$ and ammonium ferric citrate ${ }^{44}$ followed by a pyrolysis at $900^{\circ} \mathrm{C}$ under $\mathrm{Ar}$ atmosphere. Lai et al., also demonstrated a host-guest chemistry strategy to construct $\mathrm{Fe}-\mathrm{mIm}$ nanocluster (guest)@ ZIF-8 (host) precursors for Fe-N-C catalysts. ${ }^{43}$ The uniform dispersion of Fe species in the ZIF-8 precursors leads to homogeneous atomic Fe sites in catalysts. In addition to the ZIF, hemin-adsorbed bio-porphyra ${ }^{45}$ and polymer hydrogel ${ }^{46}$ were also used as $3 \mathrm{D}$ carbon/nitrogen precursors, generating atomic $\mathrm{Fe}$ dispersion. However, these catalysts still exhibited insufficient activity in acidic media. To increase activity, it is essential to uniformly disperse atomic $\mathrm{FeN}_{4}$ sties with high density into favorable carbon phases without the formation of inactive metallic aggregates.

Here, we developed a chemical doping approach to synthesizing Fe-doped ZIF precursors. Within the ZIF hydrocarbon network, Fe ions partially replace $\mathrm{Zn}$ and chemically bond with imidazolate ligands likely in the form of $\mathrm{Fe}-\mathrm{N}_{4}$ complex. This is different to physical Fe ion adsorption. One-step thermal activation is able to exclusively yield atomic $\mathrm{Fe}$ sites dispersed into porous carbon particles. The catalyst paricle sizes are tunable in a wide range from 20 to $1000 \mathrm{~nm}$. The best ORR performance was achieved on a catalyst of $50 \mathrm{~nm}$ with a halfwave potential $\left(E_{1 / 2}\right)$ of $0.85 \mathrm{~V} v s$. RHE and enhanced stability in $0.5 \mathrm{M} \mathrm{H}_{2} \mathrm{SO}_{4}$, representing one of the best PGM-free catalysts in acids. Using the atomic $\mathrm{Fe}$ catalyst as models, active sites formation process was explored through linking ORR activity and the new chemical bonds associated with $\mathrm{N}, \mathrm{C}$, and $\mathrm{Fe}$ as function of heating temperature.

\section{Results and Discussion}

\subsection{Atomic Fe catalysts with tunable particle sizes}

ZIFs are ideal 3D precursors providing $\mathrm{N}$ and $\mathrm{C}$ sources for $\mathrm{Fe}-\mathrm{N}$ $\mathrm{C}$ catalysts. We introduce active Fe species during the growth of ZIF nanocrystals by simultaneously adding $\mathrm{Fe}$ and $\mathrm{Zn}$ ions with 2methylimidazole. In addition to $\mathrm{Zn}-\mathrm{N}_{4}$ complex, the tetrahedral Fe- $\mathrm{N}_{4}$ structures likely exist in precursors (Figure 1a), which is in good agreement with the identical XRD pattern after doping (Figure S1) along with X-ray absorption spectroscopy. The subsequent one-step thermal activation is crucial for converting the $\mathrm{Fe}$ $\mathrm{N}_{4}$ complexes into active $\mathrm{FeN}_{4}$ sites embedded into carbon. $\mathrm{Zn}$ is evaporated $\left(>907^{\circ} \mathrm{C}\right)$ and generates porous carbon structures. The hydrocarbon networks in ZIF crystals were completely carbonized as evidenced by the dominant peaks at $25^{\circ}$ and $44^{\circ}$ for carbon (002) and (101) planes, respectively (Figure S1). The presence of iron species in catalysts was verified by XPS (ca. 0.5 at.\%). Unlike previous $\mathrm{Fe}-\mathrm{N}-\mathrm{C}$ catalysts, ${ }^{7}$ there is no metal aggregates such as metallic $\mathrm{Fe}$ or $\mathrm{Fe}_{3} \mathrm{C}$ phases detected in catalysts. Through vary- ing concentrations of metal salts (i.e., Fe and Zn), the sizes of ZIF dodecahedron crystals can be tuned in a wide range from $20 \mathrm{~nm}$ to $1000 \mathrm{~nm}$. The homogeneous particle morphology can be retained during thermal activation (Figure S1). Thus, particle sizes of catalysts can be continuously adjustable in the same range (Figure 1b and Figure S2). Similar to Pt nanoparticles, ${ }^{47}$ the precise size control provide a new opportunity to increase the number of PGMfree active sites and enhance mass transfer in fuel cell electrodes.

More importantly, the Fe-doped ZIF catalysts are rich in atomic Fe sites embedded into carbon particles, which is clearly identified by using high angle annular dark field (HAADF)STEM images (Figure 1c and 1d). Using EELS coupled with microscopy (the inset of Figure 1d), these isolated single atomic sites are identified to be Fe. Highly porous carbon phases are dominant in each particle without formation of metallic aggregates (Figure S3). Electron diffraction patterns further verify the absence of crystalline Fe phases or clusters in the catalyst (Figure $\mathrm{S} 3$ ). The exclusive formation of atomically dispersed Fe sites in catalysts would increase the density of active sites for improved catalytic activity and stability.
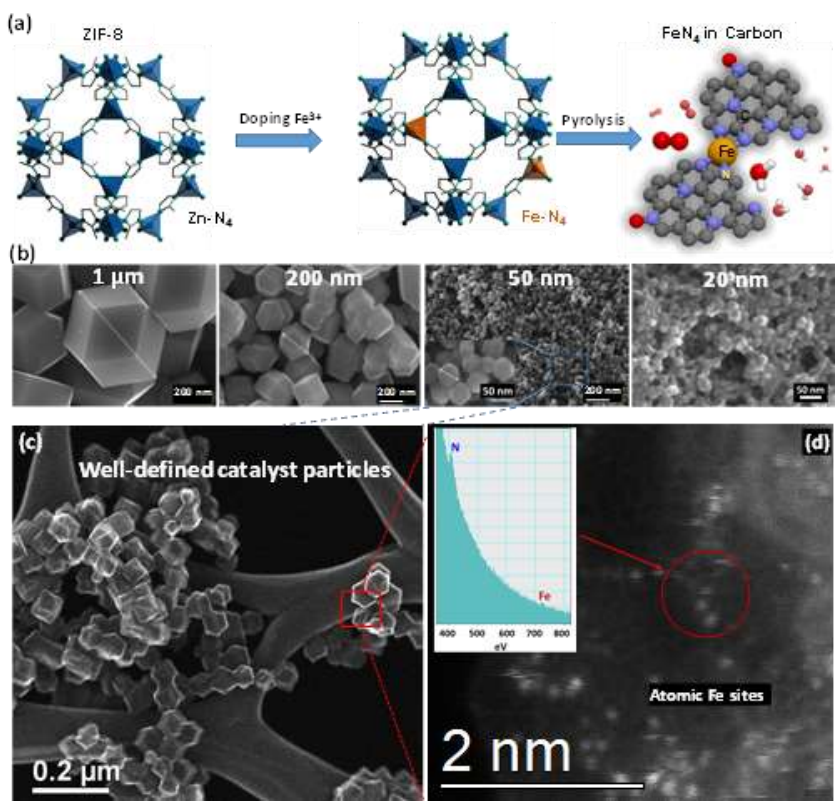

Figure 1. (a) Synthesis principles of Fe-doped ZIF-derived catalysts. (b) Accurately controlled sizes of the Fe-ZIF catalysts from 20 to $1000 \mathrm{~nm}$. (c, and d) HAADF-STEM images of the best performing Fe-doped ZIF catalyst $(50 \mathrm{~nm})$ and EELS analysis (the inset of d).

\subsection{Precursor-to-catalyst conversion via thermal activation.}

Subtle changes of morphology were carefully studied between FeZIF nanocrystals and corresponding catalysts after thermal treatments. HR-TEM and STEM images with different magnifications reveal that Fe-doped ZIF nanocrystals have well-defined rhombic dodecahedron shape (Figure 2a to 2d). The crystal surface is relatively smooth containing dominant micropore (less than 0.5 $\mathrm{nm}$ ) associated with 3D hydrocarbon networks within frameworks. After thermal treatment at $1100^{\circ} \mathrm{C}$, size and shape of ZIF crystals are nearly maintained in catalysts. The polyhedron carbon particles are clearly identified in the catalysts with roughly $10 \%$ shrunk in size (Figure 2e to $\mathbf{2 h}$ ). The corresponding carbon particles become less distinct of their facets and more porous containing abundant micropores (up to $2 \mathrm{~nm}$ ) at surfaces (Figure S3). It has been speculated that active sites are likely located inside or around micropores of carbon phases. ${ }^{37}$ Therefore, the richness of micropores in the Fe-ZIF catalyst is favorable for accommodating high density of active sites. The carbon structures in catalysts have relatively low graphitization degree showing obvious disordered and amorphous structures. The abundant defects such as 

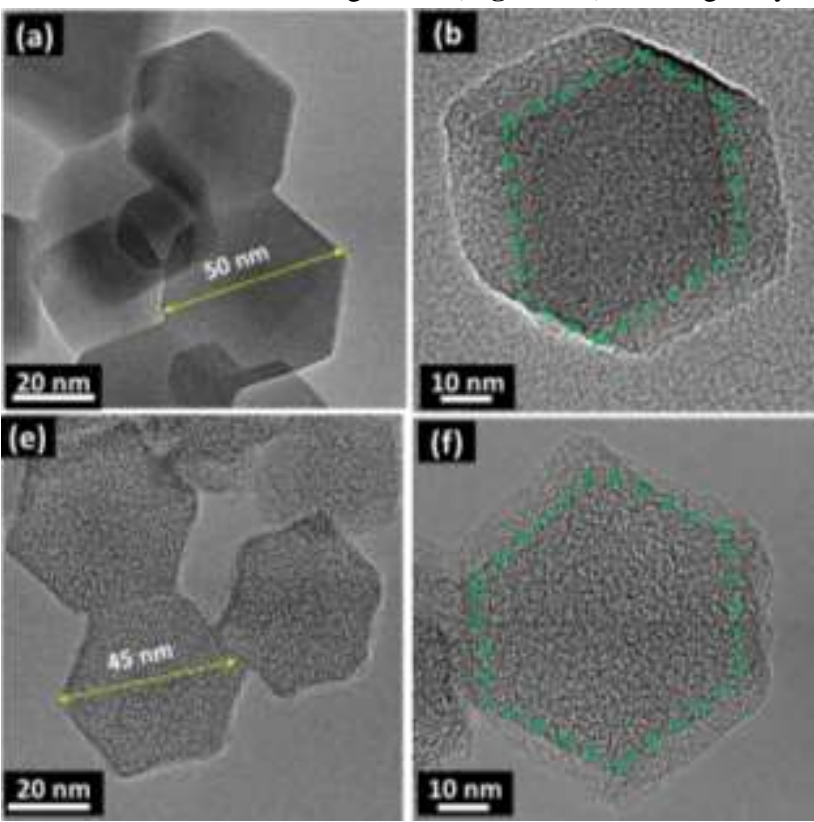

benefit ORR catalysis.

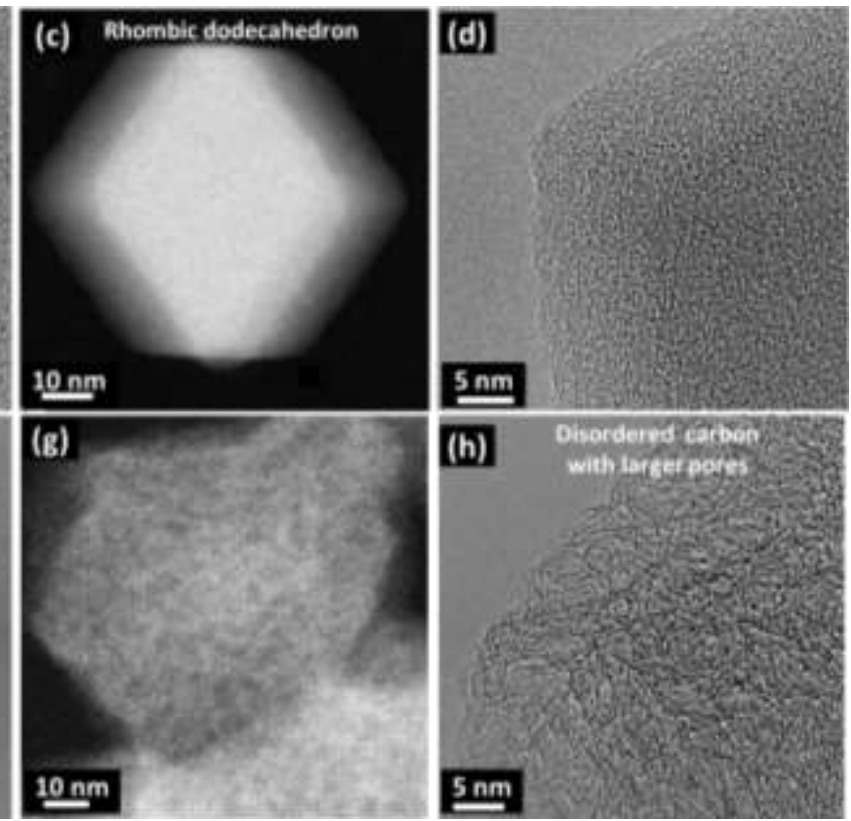

Figure 2. A comparison of morphology and microstructure between (a-d) Fe-doped ZIF nanocrystal precursors (50 nm) and (e-h) the corresponding catalyst through one-step thermal activation at $1100^{\circ} \mathrm{C}$ under $\mathrm{N}_{2}$ atmosphere for one hour.

\subsection{Size dependent ORR activity}

The ORR activity (Figure 3a) and four-electron selectivity $\left(\mathrm{H}_{2} \mathrm{O}_{2}\right.$ yield) (Figure $\mathbf{3 b}$ ) were evaluated using rotating ring disk electrode (RRDE) for both Fe-free ZIF and Fe-ZIF catalysts. Without doping of $\mathrm{Fe}$, the Zn-based ZIF catalyst showed poor activity in $0.5 \mathrm{M} \mathrm{H}_{2} \mathrm{SO}_{4}$ electrolyte with an onset potential $\left(E_{\text {onset }}\right)$ of $0.81 \mathrm{~V}$ and an $E_{1 / 2}$ of $0.59 \mathrm{~V} v s$. RHE. Compared to this well-defined Fefree ZIF catalyst, Fe doping is indispensable to boost ORR activity likely associated with the formation of more active $\mathrm{FeN}_{\mathrm{x}}$ sites relative to metal-free $\mathrm{CN}_{\mathrm{x}}$ sites. ${ }^{22}$ However, ORR activity of $\mathrm{Fe}$ ZIF catalysts is greatly dependent on their particle sizes. With particle sizes decreasing from 1000 to $50 \mathrm{~nm}$, the $E_{1 / 2}$ gradually shifts to positive direction, indicating a continuous increase of active site numbers. Further reducing particle size to $20 \mathrm{~nm}$ leads to decreased ORR activity, likely due to significant agglomeration of particles (Figure 1b) with decreased number of active sites. In addition to $E_{1 / 2}$, current densities at kinetic ranges $\left(j_{\mathrm{k}}\right.$ at $\left.0.85 \mathrm{~V}\right)$ also indicate the catalyst with a size around $50 \mathrm{~nm}$ exhibited the highest activity. Similar size dependent activity for Fe-free ZIF catalyst was also determined (Figure S4). The best Fe-ZIF catalyst $(50 \mathrm{~nm})$ achieved an $E_{1 / 2}$ of $0.85 \mathrm{~V} v s$. RHE in $0.5 \mathrm{M} \mathrm{H}_{2} \mathrm{SO}_{4}$, only $30 \mathrm{mV}$ lower than the Pt/C catalysts $\left(60 \mu \mathrm{g}_{\mathrm{Pt}} / \mathrm{cm}^{2}, E_{1 / 2}=0.88 \mathrm{~V}\right.$ in $0.1 \mathrm{M} \mathrm{HClO}_{4}$ solution even with higher $\mathrm{O}_{2}$ solubility). The respectful activity represents one of the best PGM-free catalysts for the ORR in acidic media. ${ }^{8,24,46,48-50}$ The best performing Fe-ZIF catalyst generated negligible $\mathrm{H}_{2} \mathrm{O}_{2}$ yield (less than $1 \%$ ) during the ORR, indicating a $4 \mathrm{e}^{-}$reduction pathway.

Catalyst stability was further studied using accelerated stressing tests (ASTs) by cycling potentials from 0.6 to $1.0 \mathrm{~V}$ in $\mathrm{O}_{2}$ saturated $0.5 \mathrm{M} \mathrm{H}_{2} \mathrm{SO}_{4}$. The same Fe-ZIF catalyst $(50 \mathrm{~nm})$ demonstrated much enhanced stability with the unchanged $E_{\text {onset }}$ and only a loss of $20 \mathrm{mV}$ in $E_{1 / 2}$ after 10,000 cycles (Figure 3c). For a comparison, the Fe-N-C catalyst derived from polymer (e.g., polyaniline) loses $80 \mathrm{mV}$ after 5000 cycles under identical AST conditions (Figure S4). ${ }^{34}$ The degradation of $\mathrm{Pt} / \mathrm{C}$ is also significant due to the dissolution/agglomeration of Pt nanoparticles on supports. ${ }^{51}$
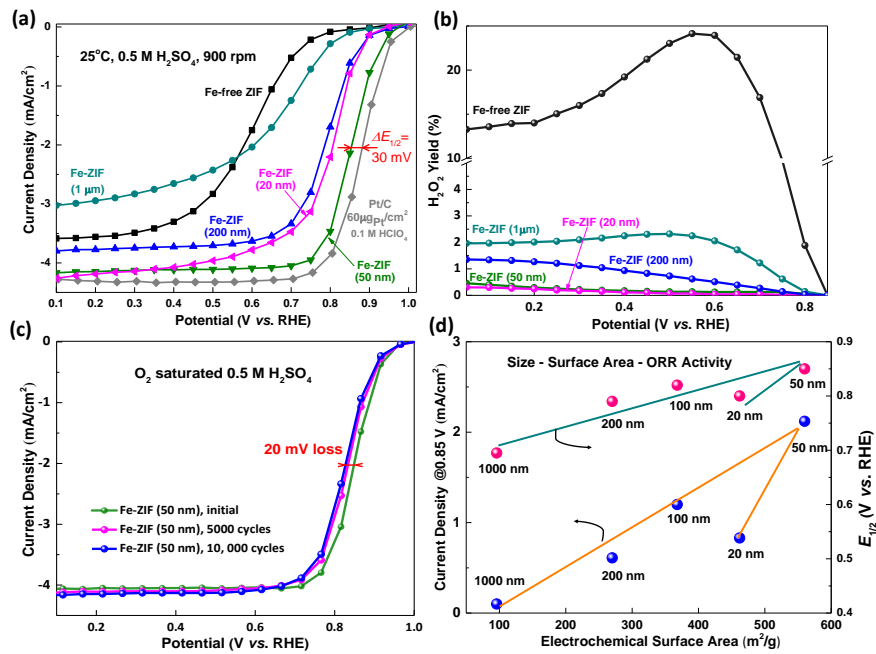

Figure 3. (a) ORR polarization plots for Fe-ZIF-derived catalysts in $0.5 \mathrm{M} \mathrm{H}_{2} \mathrm{SO}$ and $\mathrm{Pt} / \mathrm{C}$ catalysts $\left(60 \mu \mathrm{g}_{\mathrm{Pt}} / \mathrm{cm}^{2}\right)$ in $0.1 \mathrm{M} \mathrm{HClO}_{4}$ at $25{ }^{\circ} \mathrm{C}$ and $900 \mathrm{rpm}$ (b) Calculated $\mathrm{H}_{2} \mathrm{O}_{2}$ yield for Fe-ZIF catalysts as function of particle size. (c) Stability AST by using potential cycle (0.6$1.0 \mathrm{~V}$ in $\mathrm{O}_{2}$ saturated $0.5 \mathrm{M} \mathrm{H}_{2} \mathrm{SO}_{4}$. (d) The correlation between ORR activity and $S_{\mathrm{a}}$ indicating a clear size dependence.

The BET surface areas and pore size distribution of catalysts were also measured as a function of particle sizes (Figure S5 and Table S1). While BET surface area is nearly independent of particle size, meso/macropores become more dominant with a decrease of sizes. The origin of such meso/macropores is void spaces between particles that are comparable and even larger than their corresponding particle sizes. ${ }^{52} \mathrm{We}$ found that the density of active sites on catalysts is likely independent of particle sizes. XRD pattern (Figure S6), Raman (Figure S7 and Table S2), and XPS C1s (Table S3) suggest identical carbon structures in catalysts with a wide size range from 20 to $1000 \mathrm{~nm}$. XPS analysis (Figure S8 and Table S4) and elemental qualification (Table S5) further indicate that $\mathrm{N}$ doping (content and type) and $\mathrm{Fe}$ content are nearly the same for all of the studied catalysts. The dependence of ORR activity on particle sizes can be explained by using the elec- 
trochemically accessible surface area $\left(S_{\mathrm{a}}\right)$ reflected from doublelayer capacitance of catalysts (Figure S9). Considering the similar density of active sites on various catalysts, $S_{\mathrm{a}}$ is an indication of exposed number of active sites available for the ORR per unit of mass. Thus, the correlation between particle size, activity, and $S_{\text {a }}$ is established and shown in Figure 3d. ORR activity is proportionally increased with a decrease of particle size from 1000 to 50 $\mathrm{nm}$, which is associated with an increase of $S_{\mathrm{a}}$. When particle size is further reduced to $20 \mathrm{~nm}$, ORR activity turns to be decreased. This is due to significant agglomeration of small particles $(\sim 20$ $\mathrm{nm})$ losing their accessible active sites, in good agreement with decreased $S_{\text {a }}$ relative to the catalyst with isolated particle morphology $(50 \mathrm{~nm})$. Therefore, the size dependent activity is likely due to the increased number of active sites at the catalyst surfaces stemming from increased $S_{\mathrm{a}}$ exposing for the ORR. Unlike $\mathrm{Pt}$ nanoparticle catalysts, this unique feature of improving catalyst activity by controlling size of catalysts has never been reported before for PGM-free carbon catalysts. This is because previous catalysts often have highly heterogeneous morphology without accurate controls of catalyst sizes and shapes.

\subsection{Active site formation}

The effect of heating temperature (up to $1100^{\circ} \mathrm{C}$ ) on activity (Figure 4a) and $\mathrm{H}_{2} \mathrm{O}_{2}$ yields (Figure $\mathrm{S} 10$ ) was studied on the Fe-ZIF catalyst $(50 \mathrm{~nm})$. The Fe-ZIF precursor (before pyrolysis) and FeZIF-500 (treated at $500^{\circ} \mathrm{C}$ ) are unstable in acids, and thus their activities cannot be measured. In addition, there is no measurable steady-state ORR current for both Fe-ZIF-600 and Fe-ZIF-700 samples, indicating no formation of active sites yet. When the temperature was further increased to $800^{\circ} \mathrm{C}$, the catalyst started showing significant ORR activity. This suggests that $800^{\circ} \mathrm{C}$ is the minimum temperature for generating active sites in acidic media for the ORR. Higher temperature (up to $1100^{\circ} \mathrm{C}$ ) leads to enhanced activity, which likely facilitates the formation of larger number of active sites or sites with higher intrinsic activity. Notably, no product was left after a heat treatment above $1150^{\circ} \mathrm{C}$. According to the phase diagram of carbon and iron, the eutectic point is around $1147^{\circ} \mathrm{C}$, which generates liquid phase. Thus the highest possible temperature for carbonization the Fe-doped ZIF precursor is $1100^{\circ} \mathrm{C}$. To elucidate new chemical bonds associated with active site formation, the Fe-ZIF catalysts synthesized at varied temperatures were extensively characterized.

The correlation between ORR activity and overall $\mathrm{N}$ doping determined by using XPS was summarized in Figure 4b. The elemental quantification analysis (Figure S11 and Table S6) indicate that increasing heating temperature results in a decline of total $\mathrm{N}$ content due to the loss of pyridinic $\mathrm{N}$ and five-side pyrrolic N. Oppositely, the content of graphitic $\mathrm{N}$ is increased. Fe content is nearly independent of heating temperatures from 800 to $1100^{\circ} \mathrm{C}$. Similar to previous reports, ${ }^{2,30}$ the continuous decrease of $\mathrm{N}$ content does not lead to declined activity. This suggests that $\mathrm{N}$ content in catalysts might be sufficient and the nature of doping $\mathrm{N}$ (graphitic $\mathrm{N} v s$. pyridinic $\mathrm{N}$ ) in carbon is more important. Pyridinic $\mathrm{N}$ provides coordination sites to atomic $\mathrm{Fe}$ in the form of $\mathrm{FeN}_{\mathrm{x}}$, while graphitic $\mathrm{N}$ affects geometric and electric structures of carbon.

Furthermore, $800^{\circ} \mathrm{C}$ was found as the critical point for forming new bonds associated with doped $\mathrm{N}$ (Figure 4c). The major $\mathrm{N} 1 \mathrm{~s}$ peak in precursors significantly shifts to high binding energy, indicating a likely transformation of $\mathrm{Fe}-\mathrm{N}_{4}$ complex within ZIFs to active $\mathrm{Fe}-\mathrm{N}_{\mathrm{x}}$ sites embedded into carbon. It accompanies with new bond formation of pyridinic $\mathrm{N}(398.6 \mathrm{eV})$ and Fe-N moieties $(399.4 \mathrm{eV}){ }^{19,21,53}$ However, graphitic $\mathrm{N}$ is still insignificant. Up to $900^{\circ} \mathrm{C}$, both graphitic $\mathrm{N}$ and Fe-N keep increasing, suggesting increased number of active sites. However, when temperature increased from 900 to $1100^{\circ} \mathrm{C}$, such $\mathrm{Fe}-\mathrm{N}$ content remained the same, while the content of relative graphitic $\mathrm{N}$ constantly increases. This indicates that the enhanced activity was possibly contributed by the additional increased graphitic $\mathrm{N}$ up to $1100^{\circ} \mathrm{C}$. According to DFT calculation, ${ }^{32}$ doping of graphitic $\mathrm{N}$ leads to nonuniform electron distribution. This may facilitate adsorption of $\mathrm{O}_{2}$ onto adjacent carbon atoms. Similar effect of graphitic $\mathrm{N}$ on the electronic structures of $\mathrm{FeN}_{4}$ sites may generate a synergy to promote the adsorption of $\mathrm{O}_{2}$ and $\mathrm{O}=\mathrm{O}$ bond breaking on $\mathrm{FeN}_{4}$ sites. Further DFT study is needed to fully elucidate this.

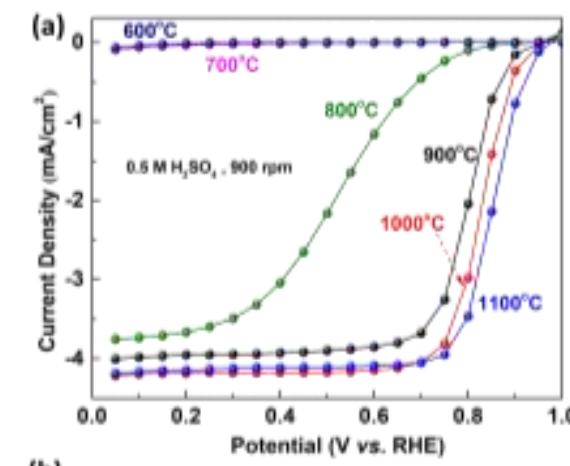

(b)
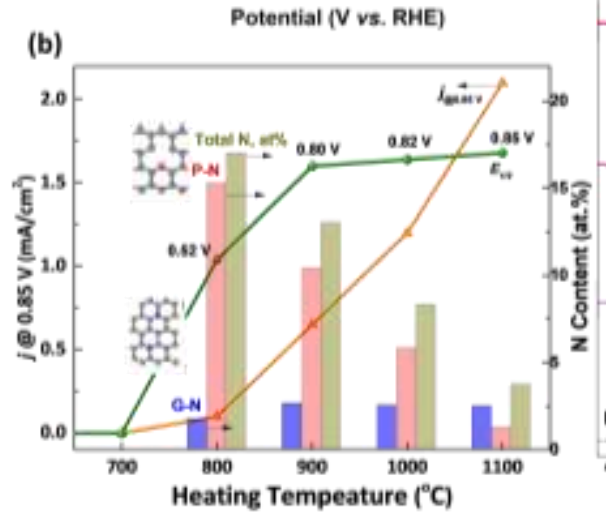
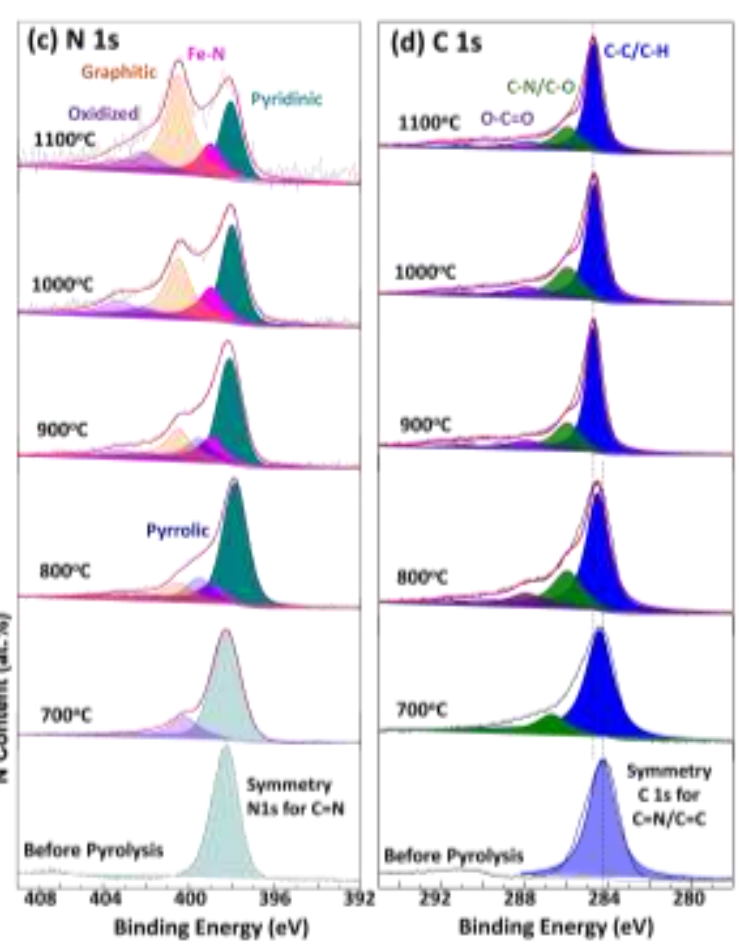

Figure 4. Active site formation during the thermal activation (a) ORR activity of Fe-ZIF catalysts prepared at various temperature (600 to $1100^{\circ} \mathrm{C}$ ). (b) Correlation of ORR activity and new bonding formation associated with doped pyridinic (P) and graphitic (G) nitrogen. Evolution of XPS N 1s (c) and C 1s (d) spectra of the Fe- ZIF catalyst with increasing heating temperatures up to $1100{ }^{\circ} \mathrm{C}$. 
The degree of carbon graphitization in catalysts is increased with temperature evidenced by gradually narrowing $\mathrm{C}-\mathrm{C}$ peaks and reduced $\mathrm{C}-\mathrm{O} / \mathrm{C}=\mathrm{O}$ species (Figure $4 \mathbf{d}$ and Table $\mathrm{S} 7$ ). XRD patterns (Figure S12) illuminate that ZIF crystals start to be decomposed at the temperature of $600^{\circ} \mathrm{C}$. Likewise, Raman spectra (Figure S13) and their fitting results (Table S8) indicate that carbonization of ZIFs occurs from $700^{\circ} \mathrm{C}$, forming graphitized $\mathrm{C}-\mathrm{C}$ bond. Increasing temperature from 800 to $1100^{\circ} \mathrm{C}$ leads to higher degree of graphitization and reduction of distortion associated with five-side ring and heteroatom doping. Thus, formation of graphitized carbon is a necessity to generate ORR activity either by providing electron transfer media and hosting $\mathrm{FeN}_{\mathrm{x}}$ active sites or even participating as part of active sites. ${ }^{23}$ Combined the HRTEM images (Figure 2), long-range ordering and local disordered structures may be favorable for the ORR with enhanced activity and stability. ${ }^{54}$

Existing DFT calculation suggested that the most likely active sites are atomically dispersed $\mathrm{Fe}$, bonded with $\mathrm{N}$ in the forms of $\mathrm{FeN}_{4}{ }^{20,25,55,56}$ Based on XPS analysis, we do detect the likely $\mathrm{FeN}_{\mathrm{x}}$ sites with obvious increases of pyridinic $\mathrm{N}$ relative to $\mathrm{Fe}$ free ZIF catalysts. To verify the hypothesis, X-ray absorption spectroscopy (XAS) were recorded for both Fe-doped ZIF precursor and catalysts treated at various temperatures (Figure 5). Fe Kedge X-ray absorption near edge structure (XANES) in Figure 5a shows that the precursor has the highest Fe oxidation state, close to $3^{+}$, as compared to $\mathrm{Fe}_{2} \mathrm{O}_{3}$ reference, which is in good agreement of using $\mathrm{Fe}^{3+}$ ions as precursors for chemical doping into ZIFs. However, upon high-temperature treatments, the oxidation state of Fe in catalysts was reduced, as evidenced from the shift of the XANES edge towards lower energy (closer to the edge of $\mathrm{FeO}$ reference). This is consistent with previous XANES measurements, which also showed that the Fe oxidation state in $\mathrm{FeN}_{4}$ is between $2^{+}$and $3^{+}$by comparing the edge slope and its shift with $\mathrm{Fe}_{2} \mathrm{O}_{3}$ and $\mathrm{FePc}$ standards. ${ }^{57}$ The broader white line (around 7133 $\mathrm{eV}$ ) for catalysts at higher temperature is indicative of less confined electron in Fe local structure due to the uncertainty principle. All these evidences indicate the formation of possible $\mathrm{FeN}_{4}$ in a well-dispersed local structure in heat-treated catalysts. Careful examination of Fe pre-edge region in the inset of Figure 5a shows the increase of peak intensity for $1100^{\circ} \mathrm{C}$ treated catalyst. This could be due to lower local structure symmetry or shorter bond length. ${ }^{58}$ When checking the Fe L-edge XANES, as shown in Figure 5b, the standard samples of $\mathrm{FeTiO}_{3}$ and $\mathrm{Fe}_{2} \mathrm{O}_{3}$ show two well-split peaks at $\sim 706$ and $\sim 708 \mathrm{eV}$ (Fe L3), an indication of $\mathrm{Fe}$ in octahedral site coordinated with 6 oxygen atoms. ${ }^{59}$ However, for the Fe-ZIF catalysts annealed at $1100^{\circ} \mathrm{C}$ with different sizes, the splitting is not very clear and only a broad Fe L3 peak is identified, which suggests the local coordination of these Fe atoms is different. Furthermore, simulation of Fe L3 XAS shows that tetrahedrally coordinated Fe will only have a broad peak, while any additional octahedrally coordinated $\mathrm{Fe}$ will split the peak into two. ${ }^{59}$ This strongly suggests that $\mathrm{Fe}$ in our catalysts is centered by 4 other atoms. This is also confirmed from the Fe K-edge extended X-ray absorption fine structure (EXAFS) in Figure 5c, as a clear shift of the first shell Fe-N/O bond length is observed in $1100^{\circ} \mathrm{C}$ treated catalyst compared to that in the precursor. Notable, similar to the chemically-defined FePc, ${ }^{57}$ the Fe-doped ZIF precursor likely contains $\mathrm{Fe}-\mathrm{N}_{4}$ complex structures. No $\mathrm{Fe}-\mathrm{Fe}$ bond is identified in the corresponding catalyst treated at $1100^{\circ} \mathrm{C}$ from EXAFS, suggesting no formation of metallic iron. To further determine whether $\mathrm{Fe}$ is coordinated with $\mathrm{N}$ or $\mathrm{O},{ }^{60}$ we performed EXAFS fitting on the first-shell of these catalysts, as shown in Figure 5d, and the fitting results are listed in Table S9. Using $\mathrm{FePc}$ structure that has $\mathrm{FeN}_{4}$ unit as the reference, all first shell of the Fe-ZIF catalysts can be well fitted with $\sim 4 \mathrm{~N}$ atoms. Higher temperature treatment leads to more well dispersed $\mathrm{FeN}_{4}$ structure as the fitted coordination number is closer to 4 , and long range disorder becomes more obvious (lower peak amplitude for $\mathrm{R}>$ $2 \AA)$. We also used Fe-O scattering paths to fit Fe-ZIF catalysts treated at $1100{ }^{\circ} \mathrm{C}$ with $\mathrm{Fe}_{2} \mathrm{O}_{3}$ as the reference (Figure S14). The obtained coordination number is close to 5 (Table S9). Considering the tetrahedral structure of Fe-ZIF catalysts suggested from $\mathrm{Fe}$ L-edge XANES, $\mathrm{FeN}_{4}$ is a more reasonable structure for the studied atomic Fe catalysts. Thus, optimal control of the thermal activation is thus very critical for generating the most active $\mathrm{FeN}_{4}$ sites in catalysts.
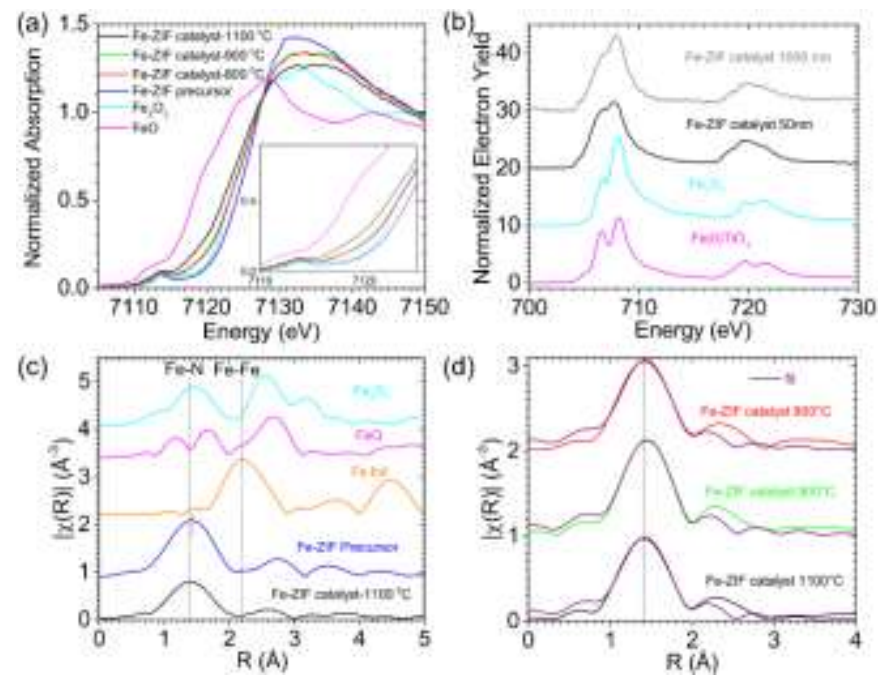

Figure 5. (a) Fe K-edge XANES with zoom-in pre-peak region in the inset, (b) Fe L-edge XANES, (c) Fe K-edge EXAFS spectra for chemically Fe-doped ZIF before and after a thermal activation, and (d) EXAFS fitting on the first-shell of catalysts prepared from different temperatures $\left(800,900\right.$ and $\left.1100^{\circ} \mathrm{C}\right)$.

\section{Conclusion}

In summary, a single atomic Fe catalyst without metallic agglomeration was developed via a chemical doping of Fe ions into ZIF networks followed by one-step thermal activation. The new PGMfree catalyst achieved ORR activity approaching Pt in challenging acidic electrolytes along with significantly enhanced stability. The chemical doping process is the key to the formation of possible $\mathrm{Fe}-\mathrm{N}_{4}$ complex connected into 3D organic framework nanocrystals. Subsequent thermal activation converts them into ORR active atomic $\mathrm{FeN}_{4}$ sites embedded into porous carbon phases. During the conversion, the particle sizes and shapes of Fe-doped ZIF polyhedron crystals are retained in the corresponding catalysts. Thus, the unique synthetic chemistry to control ZIF crystal sizes (20 to $1000 \mathrm{~nm}$ ) allows us to study the size-dependent ORR activity for PGM-free catalysts. Similar to Pt nanoparticles, PGM-free carbon catalysts thus can be engineered with improving catalytic activity through exposing increased number of active sties and generating more effective porosity for mass transfer in fuel cell electrodes.

More importantly, this work provides a series of homogenous atomic Fe catalysts, which was further studied as a model system. The active site formation process during the thermal activation was thus elucidated. A temperature of $800^{\circ} \mathrm{C}$ was identified as the critical point, forming new bonds associated with $\mathrm{N}, \mathrm{C}$, and Fe. Further increasing temperatures yield higher content of graphitic nitrogen and the possible $\mathrm{Fe}-\mathrm{N}_{4}$ species with a reduction of oxidation number of Fe between $3+$ and 2+. The possible synergistic effect between graphitic $\mathrm{N}$ and $\mathrm{FeN}_{4}$ is responsible for enhanced activity with an increase of heating temperature. XAS characterization further provides strong evidence that $\mathrm{FeN}_{4}$ is very likely associated with the atomic Fe sites, which is favorable at higher temperature (i.e., $1100^{\circ} \mathrm{C}$ ). The chemically Fe-doped MOF ap- 
proach would be an effective solution to generate uniform dispersion of atomic $\mathrm{FeN}_{4}$ sites into carbon, capable of significantly narrowing down the performance gap with Pt catalysts in challenging acidic media. For future catalyst design, one key consideration is to increase the density of atomic Fe sites by preventing their clustering, which could be realized by strengthening the $\mathrm{Fe}-$ $\mathrm{N}$ bonding in precursors or using multiple nitrogen precursors.

\section{ASSOCIATED CONTENT}

\section{Supporting Information}

Experimental details and additional result and discussion The Supporting Information is available free of charge on the ACS Publications website.

\section{AUTHOR INFORMATION}

\section{Corresponding Author}

Corresponding authors: yuyan.shao@pnnl.gov (Y. Shao) and gangwu@buffalo.edu (G. Wu).

\section{ACKNOWLEDGMENT}

This work is financially supported from the start-up funding from the University at Buffalo, SUNY and National Science Foundation (CBET-1604392). G. W. and Y. S. thank the support from U.S. DOE EERE Fuel Cell Technologies Office. Z. F. thanks the Callahan Faculty Scholar Endowment Fund from Oregon State University. HR-TEM was conducted in the William R. Wiley Environmental Molecular Sciences Laboratory (EMSL) at Pacific Northwest National Laboratory (PNNL), a DOE User Facility. STEM/EELS analysis were performed at the Center for Functional Nanomaterials, a U.S. DOE Office of Science Facility, at Brookhaven National Laboratory under Contract No. DESC0012704. XAS measurements were done at 5BM-D of DNDCAT and 4ID-C at Advanced Photon Source (APS) of Argonne National Laboratory (ANL). We thank Drs. Karren More and David Cullen (Oak Ridge National Laboratory) for atomic iron microscopy analysis and the valuable discussion with Dr. Piotr Zelenay (Los Alamos National Laboratory).

\section{REFERENCES}

(1) Spendelow, J.; Papageorgopoulos, D. Fuel Cells 2011, 11, 775.

(2) Wu, G.; Zelenay, P. Acc. Chem. Res. 2013, 46, pp 1878.

(3) Gewirth, A. A.; Thorum, M. S. Inorg. Chem. 2010, 49, 3557.

(4) Strickland, K.; Miner, E.; Jia, Q.; Tylus, U.; Ramaswamy, N.; Liang, W.; Sougrati, M.-T.; Jaouen, F.; Mukerjee, S. Nat. Commun. 2015, 6 .

(5) Nallathambi, V.; Lee, J.-W.; Kumaraguru, S. P.; Wu, G.; Popov, B. N. J. Power Sources 2008, 183, 34.

(6) Lefèvre, M.; Proietti, E.; Jaouen, F.; Dodelet, J.-P. Science 2009, 324,71 .

(7) Wu, G.; More, K. L.; Johnston, C. M.; Zelenay, P. Science 2011, $332,443$.

(8) Serov, A.; Artyushkova, K.; Atanassov, P. Adv. Energy Mater. 2014, 4, 1301735.

(9) Singh, D.; Tian, J.; Mamtani, K.; King, J.; Miller, J. T.; Ozkan, U. S. J. Catal. 2014, 317, 30.

(10) Barkholtz, H. M.; Liu, D.-J. Mater. Hori. 2017, 4, 20.

(11) Dai, L.; Xue, Y.; Qu, L.; Choi, H.-J.; Baek, J.-B. Chem. Rew. 2015, 115, 4823.

(12) Osgood, H.; Devaguptapu, S. V.; Xu, H.; Cho, J. P.; Wu, G. Nano Today 2016, 11, 601.

(13) Chen, C.-F.; King, G.; Dickerson, R. M.; Papin, P. A.; Gupta, S.; Kellogg, W. R.; Wu, G. Nano Energy 2015, 13, 423.

(14) Lee, K.; Ishihara, A.; Mitsushima, S.; Kamiya, N.; Ota, K.-i. Electrochim. Acta 2004, 49, 3479.
(15) Zhu, C.; Fu, S.; Song, J.; Shi, Q.; Su, D.; Engelhard, M. H.; Li, X.; Xiao, D.; Li, D.; Estevez, L. Small 2017, 13.

(16) Zhou, R.; Zheng, Y.; Jaroniec, M.; Qiao, S.-Z. ACS Catal. 2016, 6,4720 .

(17) Wu, Q.; Yang, L.; Wang, X.; Hu, Z. Acc. Chem. Res. 2017, 50, 435.

(18) Wu, G.; Santandreu, A.; Kellogg, W.; Gupta, S.; Ogoke, O.; Zhang, H.; Wang, H.-L.; Dai, L. Nano Energy 2016, 29, 83.

(19) Workman, M. J.; Serov, A.; Tsui, L.-k.; Atanassov, P.; Artyushkova, K. ACS Energy Lett. 2017, 2, 1489.

(20) Kattel, S.; Wang, G. J. Mater. Chem. A 2013, 1, 10790.

(21) Jiang, W.-J.; Gu, L.; Li, L.; Zhang, Y.; Zhang, X.; Zhang, L.-J.; Wang, J.-Q.; Hu, J.-S.; Wei, Z.; Wan, L.-J. J. Am. Chem. Soc. 2016, $138,3570$.

(22) Holby, E. F.; Wu, G.; Zelenay, P.; Taylor, C. D. J. Phys. Chem. C 2014, 118, 14388.

(23) Kattel, S.; Wang, G. The journal of physical chemistry letters 2014, 5,452 .

(24) Zitolo, A.; Goellner, V.; Armel, V.; Sougrati, M.-T.; Mineva, T.; Stievano, L.; Fonda, E.; Jaouen, F. Nat. Mater. 2015, 14, 937.

(25) Jia, Q.; Ramaswamy, N.; Hafiz, H.; Tylus, U.; Strickland, K.; Wu, G.; Barbiellini, B.; Bansil, A.; Holby, E. F.; Zelenay, P. ACS Nano 2015, 9, 12496.

(26) Gupta, S.; Zhao, S.; Ogoke, O.; Lin, Y.; Xu, H.; Wu, G. ChemSusChem 2017, 10, 774.

(27) Fang, X.; Jiao, L.; Yu, S. H.; Jiang, H. L. ChemSusChem 2017, $10,3019$.

(28) Xie, N. H.; Yan, X. H.; Xu, B. Q. ChemSusChem 2016, 9, 2301.

(29) Li, Q.; Wang, T.; Havas, D.; Zhang, H.; Xu, P.; Han, J.; Cho, J.; Wu, G. Advanced Science 2016, 3, 1600140.

(30) Wu, G.; Mack, N. H.; Gao, W.; Ma, S.; Zhong, R.; Han, J.; Baldwin, J. K.; Zelenay, P. ACS Nano 2012, 6, 9764.

(31) Wu, G.; Nelson, M.; Ma, S.; Meng, H.; Cui, G.; Shen, P. K. Carbon 2011, 49, 3972.

(32) Li, Q.; Xu, P.; Gao, W.; Ma, S.; Zhang, G.; Cao, R.; Cho, J.; Wang, H.-L.; Wu, G. Adv. Mater. 2014, 26, 1378.

(33) Wu, G.; More, K. L.; Xu, P.; Wang, H.-L.; Ferrandon, M.; Kropf, A. J.; Myers, D. J.; Ma, S.; Zelenay, P. Chem. Commun. 2013, 49, 3291.

(34) Wu, G.; Nelson, M. A.; Mack, N. H.; Ma, S.; Sekhar, P.; Garzon, F. H.; Zelenay, P. Chem. Commun. 2010, 46, 7489.

(35) Gao, W.; Havas, D.; Gupta, S.; Pan, Q.; He, N.; Zhang, H.; Wang, H.-L.; Wu, G. Carbon 2016, 102, 346.

(36) Ma, S.; Goenaga, G. A.; Call, A. V.; Liu, D.-J. Chem. - A Euro. J. 2011, 17, 2063.

(37) Proietti, E.; Jaouen, F.; Lefèvre, M.; Larouche, N.; Tian, J.; Herranz, J.; Dodelet, J.-P. Nat. Commun. 2011, 2, 416.

(38) Xia, W.; Zhu, J.; Guo, W.; An, L.; Xia, D.; Zou, R. J. Mater. Chem. A 2014, 2, 11606.

(39) Zhao, D.; Shui, J.-L.; Grabstanowicz, L. R.; Chen, C.; Commet, S. M.; Xu, T.; Lu, J.; Liu, D.-J. Adv. Mater. 2014, 26, 1093.

(40) Zhang, H.; Osgood, H.; Xie, X.; Shao, Y.; Wu, G. Nano Energy 2017, 31, 331 .

(41) Lu, J.; Zhou, W.; Wang, L.; Jia, J.; Ke, Y.; Yang, L.; Zhou, K.; Liu, X.; Tang, Z.; Li, L.; Chen, S. ACS Catal. 2016, 6, 1045.

(42) Mahmood, A.; Guo, W.; Tabassum, H.; Zou, R. Adv. Energy Mater. 2016, 6, doi: 10.1002/aenm.201600423.

(43) Lai, Q.; Zheng, L.; Liang, Y.; He, J.; Zhao, J.; Chen, J. ACS Catal. 2017, 7, 1655.

(44) Ye, Y.; Cai, F.; Li, H.; Wu, H.; Wang, G.; Li, Y.; Miao, S.; Xie, S.; Si, R.; Wang, J.; Bao, X. Nano Energy 2017, 38, 281.

(45) Zhang, Z.; Gao, X.; Dou, M.; Ji, J.; Wang, F. Small 2017, 13, 1604290.

(46) Qiao, Z.; Zhang, H.; Karakalos, S.; Hwang, S.; Xue, J.; Chen, M.; Su, D.; Wu, G. Appl. Catal. B: Environ. 2017, 219, 629.

(47) Shao, M.; Peles, A.; Shoemaker, K. Nano Lett. 2011, 11, 3714.

(48) Dodelet, J. P.; Chenitz, R.; Yang, L.; Lefèvre, M. ChemCatChem 2014, 6, 1866.

(49) Yuan, S.; Shui, J. L.; Grabstanowicz, L.; Chen, C.; Commet, S.; Reprogle, B.; Xu, T.; Yu, L.; Liu, D. J. Angew. Chem. Int. Ed. 2013, 52, 8349 . 
(50) Wang, X.-J.; Zhang, H.; Lin, H.; Gupta, S.; Wang, C.; Tao, Z.; Fu, H.; Wang, T.; Zheng, J.; Wu, G. Nano Energy 2016, 25, 110.

(51) Li, Q.; Pan, H.; Higgins, D.; Cao, R.; Zhang, G.; Lv, H.; Wu, K.; Cho, J.; Wu, G. Small 2015, 11, 1443.

(52) Zaręba, J. K.; Nyk, M.; Samoć, M. Crys. Growth Des. 2016, 16, 6419.

(53) Ferrandon, M.; Kropf, A. J.; Myers, D. J.; Artyushkova, K.; Kramm, U.; Bogdanoff, P.; Wu, G.; Johnston, C. M.; Zelenay, P. J. Phys. Chem. C 2012, 116, 16001.

(54) Wu, G. Frontiers in Energy 2017, 11, 286.
(55) Subramanian, N. P.; Li, X.; Nallathambi, V.; Kumaraguru, S. P.; Colon-Mercado, H.; Wu, G.; Lee, J.-W.; Popov, B. N. J. Power Sources 2009, 188, 38.

(56) Ferrandona, M.; Wang, X.; Kropfa, A. J.; Myersa, D. J.; Wu, G.; Johnston, C. M.; Zelenay, P. Electrochim. Acta 2013, 110, 282.

(57) Deng, D.; Chen, X.; Yu, L.; Wu, X.; Liu, Q.; Liu, Y.; Yang, H.; Tian, H.; Hu, Y.; Du, P. Sci. Adv. 2015, 1, e1500462.

(58) Carta, D.; Casula, M. F.; Falqui, A.; Loche, D.; Mountjoy, G.; Sangregorio, C.; Corrias, A. J. Phys. Chem. C 2009, 113, 8606.

(59) Peak, D.; Regier, T. Environ. Sci. Tech. 2012, 46, 3163.

(60) Feng, Z.; Ma, Q.; Lu, J.; Feng, H.; Elam, J.; Stair, P. C.; Bedzyk, M. RSC Adv. 2015, 5, 103834.

Table of Content

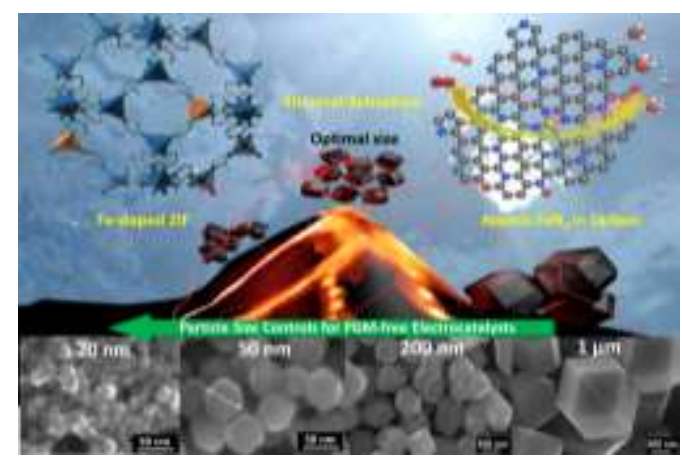

